\title{
Experiences with 7 years of acidification in Denmark- SyreN system, a commercial method to fertilize with sulphate while reducing animal slurry ammonia emission
}

\author{
M. Toft *, C. T. Madsen \\ BioCover A/S, Veerst skovvej 6, 6600 Vejen Denmark
}

\begin{abstract}
How to cite this paper: M. Toft. C. T. Madsen. (2019) Experiences with 7 years of acidification in Denmark-SyreN system, a commercial method to fertilize with sulphate while reducing animal slurry ammonia emission. International Journal of Food Science and Agriculture, 3(3), 192-195.
\end{abstract}

DOI: 10.26855/ijfsa.2019.09.007

*Corresponding author: M. Toft, BioCover A/S, Veerst skovvej 6, 6600 Vejen Denmark.

Email:mt@biocover.dk

\begin{abstract}
In 2009 a group of companies were assembled (Aarhus University, SEGES, BioCover A/S and Grundfos ) and committed to a joint development project "SyreN" - technology for field acidification of slurry, with support from the Danish ministry for development and innovation.

The group defined and created a demand specification for using sulfuric acid together with a slurry tanker during application with the purpose of reducing ammonia emission, later called "field acidification". Another effect of the sulfuric acid was the addition of sulphate to slurry. Following a successful research evaluation, the system was developed by BioCover to a pilot scale system for tests and following used in commercial slurry application. The commercial product was named SyreN.

Today 120 SyreN units are operative in Denmark, acidifying approx. 5.350.000 $\mathrm{m}^{3}$ slurry/year, and do so with an acid amount that often corresponds with the sulphur need by the crops.
\end{abstract}

\section{Keywords}

SyreN system, acidification, ammonia emission

\section{The history of field acidification}

Denmark has a large intensive livestock production consisting of 1.55 million cattle and 12.3 million pigs (Danmarks statistik, 2017) with an assumed yearly production of 38 million $\mathrm{m}^{3}$ slurry(Nielsen et al., 2017). The handling of the produced slurry releases airborne ammonia $\left(\mathrm{NH}_{3}\right)$ (Sutton, Erisman, Dentener, \& Moller, 2008). Deposition of $\mathrm{NH}_{3}$ causes acidification and eutrophication of natural ecosystems (Fangmeier, Hadwiger-Fangmeier, Eerden, \& Jäger, 1994). Furthermore $\mathrm{NH}_{3}$ contributes to airborne PM2.5 and PM10 particles that can be a health hazard (Erisman \& Schaap, 2004). Due to the risk of $\mathrm{NH}_{3}$ emission, Denmark has in accordance to the Goteborg protocol, been obligated to reduce the $\mathrm{NH}_{3}$ emission by approx. 20.000 tons (or $24 \%$ of the 2005 emission) within the year 2020 (Gothenburg protocol, 2005). As a means to reach the goal, a new general requirement to inject slurry on grasslands and black soils was introduced in 2011 (Husdyrgødningsbekendtgørelsen, 2017). As an addition to the new legislation, technologies accepted on the Danish environmental protection agencies - environmental technology list, can replace the injection demands if the technology is equal or better at reducing $\mathrm{NH}_{3}$ (25\% reduction, compared to band hose). Based on a VERA verification, the SyreN field acidification technology, was accepted on the technology list with a reduction effect of 49\% (VERA, 2012) and 40\% (Environmental technology list, 2017) accordingly for cattle and pig slurry. As a general requirement acidifying to $\mathrm{pH} 6.4$ or lower, was therefore accepted as supplementary technology to injection [1-5].

In 2011 approximately 4\% of the Danish slurry was acidified using the SyreN acidification technology, in 2015 this had grown to $14 \%$. In total, $20 \%$ of the Danish slurry was acidified in 2015 , SyreN has therefore become the most widely used acidification technology (Nielsen et al., 2017). 


\section{Introduction to acidification}

So far the only commercially used chemical to acidify slurry is concentrated sulphuric acid $\left(\mathrm{H}_{2} \mathrm{SO}_{4}\right)$. The acid is a waste product from the industry and therefore has a very competitive price compared to other acids. Furthermore the sulphur content is a mineral fertilizer for crops (Marschner, 2012), which is attractive to farmers and leaves no waste. Due to practical reasons, slurry acidification only takes place in three different ways: Acid added to the slurry in the animal housing (designated "barn acidification"), acid added to the slurry in the storage tank (designated "storage acidification") and acid added to the slurry during field application (designated "field acidification") (Fangueiro, Hjorth, \& Gioelli, 2015). Which method is the best, depends on where in the chain of slurry handling there is a need for $\mathrm{NH}_{3}$ reduction; the earlier in the chain, the more reduction can be obtained. Barn acidification has the feature that it is the best $\mathrm{NH}_{3}$ emission reducing technology since it reduces emission at the source. Storage acidification, used to acidify slurry when entering the storage facility, has the feature that it reduces $\mathrm{NH}_{3}$ emission from the storage and reduces emission during application of slurry to the field. However, most storage acidification takes place shortly before application and has the same effect as field acidification. Field acidification only reduces $\mathrm{NH}_{3}$ emission during field application, but does so with a much lower acid consumption than barn- or storage acidification. Acid consumption is much higher in barn- and storage acidification, because $\mathrm{pH} 5.5$ is required to make the slurry $\mathrm{pH}$ storage stable. A storage stable $\mathrm{pH}$ is required because acidification to levels above, increases the risk that $\mathrm{pH}$ re-establishes at the initial level. As a general rule of thumb, $7.5 \mathrm{~L}$ acid $/ \mathrm{m}^{3}$ slurry is required in barn- and storage acidification (Stevens, Laughlin, \& Frost, 1989) and 2.5 L/m3 for field acidification (Seidel, Pacholski, Nyord, Vestergaard, \& Kage, 2014). Fermented slurry (slurry from biogas installations) is an exception; in comparison to unfermented slurry it requires a lot of acid to reduce slurry $\mathrm{pH}$. As a general rule of thumb, fermented slurry requires $5 \mathrm{~L} / \mathrm{m}^{3}$ with field acidification to reach $\mathrm{pH} 6.4$, and the other acidification technologies are far above reasonable use. In addition, field acidification can adjust the dose rate of sulfuric acid to meet crop requirements for sulphate fertilizer with good economic results. The Danish SEGES, has estimated cost for barn- and storage acidification at 1.06 Euro pr. $\mathrm{m} 3$ and field acidification at 0.86 Euro pr. m3 (Status, economy and considerations by acidification of slurry - Erik Sindhoj - RISE, 11.) not including value of acidification as a fertilizer.

\subsection{Concentrated sulphuric acid as a sulphate fertilizer}

Sulphur deposition in Denmark has dropped from over average $300 \mathrm{~kg} \mathrm{~S} / \mathrm{ha}$ in the early 80 's to just $3.7 \mathrm{~kg} \mathrm{~S} / \mathrm{ha}$ in 2015 (Nielsen et al., 2017). This has increased a growing need for sulphate as fertilizer to keep crop yield. From the now 6 years of operation with the SyreN technology, we have seen a huge variation in the use of the system depending on local needs - the higher the crop need for sulphur, the better the economics. It is not unusual to see yield increases of $5 \mathrm{Hkg} / \mathrm{ha}$ in rape, as it is hard to find fertilizers that satisfy the high consumption of sulphate. A good way to address the need for sulphate in rape, is to replace expensive fertilizers such as ammonium sulphate NS 21-24 with a combination of sulfuric acid and conventional fertilizers such as NS 28-5. This reduces the purchase price for rape significantly. In praxis, a lot of farmers only use slurry as a fertilizer for grassland. The effect of the sulphur in slurry is then a major yield increase from $20 \%$ to $32 \%$ as measured in Sweden (Merskörd av vall i svenska fältforsök - Baltic Slurry Acidification - Erik Sindhoj - RISE)

Table 1. Needed acid amount in litres to meet the crops sulphur requirement

\begin{tabular}{|c|c|c|c|c|}
\hline \multicolumn{5}{|c|}{ Sulphur requirement } \\
\hline \multirow{3}{*}{$\begin{array}{l}\text { Slurry amount, sulphur } \\
\text { requirement and needed } \\
\text { acid addition }\end{array}$} & \multicolumn{2}{|c|}{ Winter wheat } & \multicolumn{2}{|c|}{ Winter rape } \\
\hline & Clay soil & Sandy soil & Clay soil & Sandy soil \\
\hline & $15 \mathrm{~kg} \mathrm{~S} / \mathrm{ha}$ & $12 \mathrm{~kg} \mathrm{~S} / \mathrm{ha}$ & $35 \mathrm{~kg} \mathrm{~S} / \mathrm{ha}$ & $30 \mathrm{~kg} \mathrm{~S} / \mathrm{ha}$ \\
\hline $10 \mathrm{~m} 3 / \mathrm{ha}$ & $2.6 \mathrm{~L} / \mathrm{m}^{3}$ & $2.1 \mathrm{~L} / \mathrm{m}^{3}$ & $6.1 \mathrm{~L} / \mathrm{m}^{3}$ & $5.3 \mathrm{~L} / \mathrm{m}^{3}$ \\
\hline $20 \mathrm{~m} 3 / \mathrm{ha}$ & $1.3 \mathrm{~L} / \mathrm{m}^{3}$ & $1.1 \mathrm{~L} / \mathrm{m}^{3}$ & $3.1 \mathrm{~L} / \mathrm{m}^{3}$ & $2.6 \mathrm{~L} / \mathrm{m}^{3}$ \\
\hline $30 \mathrm{~m} 3 / \mathrm{ha}$ & $0.9 \mathrm{~L} / \mathrm{m}^{3}$ & $0.7 \mathrm{~L} / \mathrm{m}^{3}$ & $2.0 \mathrm{~L} / \mathrm{m}^{3}$ & $1.8 \mathrm{~L} / \mathrm{m}^{3}$ \\
\hline $40 \mathrm{~m} 3 / \mathrm{ha}$ & $0.7 \mathrm{~L} / \mathrm{m}^{3}$ & $0.5 \mathrm{~L} / \mathrm{m}^{3}$ & $1.5 \mathrm{~L} / \mathrm{m}^{3}$ & $1.3 \mathrm{~L} / \mathrm{m}^{3}$ \\
\hline $50 \mathrm{~m} 3 / \mathrm{ha}$ & $0.5 \mathrm{~L} / \mathrm{m}^{3}$ & $0.4 \mathrm{~L} / \mathrm{m}^{3}$ & $1.2 \mathrm{~L} / \mathrm{m}^{3}$ & $1.1 \mathrm{~L} / \mathrm{m}^{3}$ \\
\hline
\end{tabular}




\subsection{The practical handling of acid}

The SyreN unit is positioned in the front hitch of the tractor, which facilitates easy loading of the IBC (IBC -Intermediate Bulk Carrier), and offsets weight from the slurry tanker to the tractor. A special feature of SyreN is the use of a transportable IBC container for sulfuric acid. Using an IBC creates a safe to use system, as there is no refilling or handling of the acid. Refilling of the IBC is handled by the acid distributor, which transports the acid to the IBC storage location with a truck and refills the IBC. All that the user has to do is load the IBC onto the SyreN pallet forks and connect the IBC by a dry coupler. In addition, the IBC is standard approved for public road transportation under the ADR rules. Another topic that makes SyreN safe is that its automatic, a minimum human interaction limits human errors. SyreN has 7 build in sensors and constantly monitors 7 sensors on the tractor to prevent acid from accidentally escaping the system. Example on some of the sensors and functions: acid pressure sensor; which monitors sudden increases or decreases in pressure, tree-way valve position; to prevent acid entering the slurry wagon, slurry flow sensor; to monitor that slurry is flowing, tractor speed; to monitor that the slurry tanker is moving as no acid can be injected without movement.

In 2017, 128 SyreN units where operative in Denmark, Sweden, Germany, Lithuania and Finland adding approx. 16.000 $\mathrm{m}^{3}$ of concentrated sulfuric acid to approx. $5.350 .000 \mathrm{~m}^{3}$ slurry. In total during the last 7 years approx. $88.200 \mathrm{~m}^{3}$ acid and approx. 29.000.000 $\mathrm{m}^{3}$ slurry, has been applied without any acid spillage or human accidents. The system has proven itself safe to use and legal for road transport in all regions.

\section{Additional advances with SyreN}

Today SyreN is much more than "just" acidification. Since the beginning an additional storage tank has been standard on SyreN so iron-sulphate $\left(\mathrm{FeSO}_{4}\right)$ could be added as a smell reductant. However, the use of $\mathrm{FeSO}_{4}$ never became widely used. There was little commercial interest in the marked to pay for odour reduction. Today, the use of the additive tank is becoming increasingly important.

- The addition of micro nutrients magnesium $\left(\mathrm{Mg}^{+}\right)$, potassium $\left(\mathrm{K}^{+}\right)$

- Use of foam stabilizer to further reduce ammonia emission.

- Injection of nitrogen inhibitor to prolong the biological transformation of $\mathrm{NH}_{4}^{+}$to $\mathrm{NO}_{3}{ }^{-}$and thus a $50 \%$ reduction in leaching to ground water

The third use is most common with commercial products like PIADIN, N-lock and Vizura. The success has been mostly because of a good strategy for slurry application on maize and slurry application in the autumn, because application on these has a potential high $\mathrm{N}$ loss through leaching to the ground water.

\section{Future}

Acidification and the SyreN system has recently received BAT status in the EU NEC and IED Directives. This makes acidification an accepted technology on a par with dribble bar- and injection systems - only it is less expensive and with a better- and more dependable effect. The European change away from broadcasting technology will now open the markets for acidification technology to become a standard equal to band spreading and injection.

The newest product addition - addition of nitrogen slurry in combination with a logistic route optimising system will be introduced in 2018. It uses anhydrous ammonia $-\mathrm{NH}_{4}{ }^{+}$- or liquid N32. Both nitrogen additions serve to stretch the slurry application ability of the slurry tanker, eliminating 30\% field traffic and increasing application efficiency with 5\% - and increasing slurry utilisation rate with $10 \%$. This makes SyreN system a multipurpose system to be used with all types of slurry application - including injection systems in a most profitable manner [6-10].

In addition, a new agenda for reduction of GHG gasses will promote the use of acidification technology, as it may reduce methane gas emission with $70 \%$.

\section{Conclusion}

SyreN system, a commercial technology to reduce both ammonia emission (50-70\%) through acidification and nitrate leaching $(50 \%)$ through addition of nitrogen inhibitor has been presented. In addition, Sulphur fertilization through 
slurry application eliminates necessity of using NS fertilizers in certain crops. EU BAT approval makes the technology competitive in all EU markets and a new logistic planning system in combination with nitrogen injection in the slurry reduces field traffic with $30 \%$ and increases slurry utilization rate with $10 \%$ [11-14].

\section{References}

[1] Danmarks statistik. (2017). Husdyr (http://www.dst.dk/da/Statistik/emner/erhvervslivets-sektorer/landbrug-gartneriog-skovbrug/husdyr) Retrieved 5 june, 2017

[2] Environmental technology list. (2017). http://eng.mst.dk/topics/agriculture/environmental-technologies-forlivestock-holdings/land-applied-manure/ Retrieved 5 june, 2017

[3] Erisman, J. W., \& Schaap, M. (2004). The need for ammonia abatement with respect to secondary PM reductions in Europe. Environ Pollut, 129(1), 159-163.

[4] Fangmeier, A., Hadwiger-Fangmeier, A., Eerden, L. V. d., \& Jäger, H. J. (1994). Effects of atmospheric ammonia on vegetation - a review. Environ Pollut, 86, 43-82.

[5] Fangueiro, D., Hjorth, M., \& Gioelli, F. (2015). Acidification of animal slurry--a review. J Environ Manage, 149, 46-56. doi: 10.1016/j.jenvman.2014.10.001

[6] 1999 Protocol to Abate Acidification, Eutrophication and Ground-level Ozone to the Convention on Long-range Transboundary Pollution (2005).

[7] Husdyrgødningsbekendtgørelsen, BEK nr 374 af 19/04/2017 (2017).

[8] Marschner, P. (2012). Mineral nutrition of higher plants (Vol. 3): Acedemic press.

[9] Nielsen, O.-K., Plejdrup, M. S., Winther, M., Mikkelsen, M. H., Nielsen, M., Fauser, P., . . Thomsen, M. (2017). Annual Danish Informative Inventory Report to UNECE. Emission inventories from the base year of the protocols to year 2015. Aarhus University, DCE - Danish Centre for Environment and Energy,. Scientific Report from DCE - Danish Centre for Environment and Energy http://dce2.au.dk/pub/SR222.pdf, 222.

[10] Seidel, A., Pacholski, A., Nyord, T., Vestergaard, A., \& Kage, H. (2014). Reduction of ammonia losses after [1] spreading of cattle slurry to grassland by acidification and injection. Summary of two years experiments.

[11] Stevens, R. J., Laughlin, R. J., \& Frost, J. P. (1989). Effect of acidification with sulphuric acid on the volatilization of ammonia from cow and pig slurries. Journal of Agricultural Science, 113, 389-395.

[12] Status, economy and considerations by acidification of slurry - Erik Sindhoj - RISE, 11.

[13] Merskörd av vall i svenska fältforsök - Baltic Slurry Acidification - Erik Sindhoj - RISE

[14] Sutton, M. A., Erisman, J. W., Dentener, F., \& Moller, D. (2008). Ammonia in the environment: from ancient times to the present. Environ Pollut, 156(3), 583-604. doi: 10.1016/j.envpol.2008.03.013 VERA. (2012). VERA verification statement (SyreN). 